\title{
Centrally Administered Opioid Peptides Stimulate Saccharin Intake in Nondeprived Rats
}

\author{
BLAKE A. GOSNELL AND MARK J. MAJCHRZAK \\ University of Michigan, Department of Psychiatry \\ University Hospital, 8D8806, Box 0116, Ann Arbor, MI 48109-0116
}

Received 28 February 1989

\begin{abstract}
GOSNELL, B. A. AND M. J. MAJCHRZAK. Centrally administered opioid peptides stimulate saccharin intake in nondeprived rats. PHARMACOL BIOCHEM BEHAV 33(4) 805-810, 1989. - Endogenous opioid peptides are thought to play a role in mediating the pleasurable or rewarding aspects of the ingestion of certain foods and liquids. We therefore measured the effects of central administration of selective opioid agonists and naloxone on the intake of two concentrations of saccharin solution. All tests were performed on nondeprived rats, such that the taste of the solutions provided the primary incentive to consume. Intracerebroventricular (ICV) administration of the selective $\mathrm{mu}$ agonist [D-Ala ${ }^{2}, \mathrm{MePhe}^{4}, \mathrm{Gly}-\mathrm{ol}^{5}$ ]enkephalin (DAGO) and the selective delta agonist Tyr-D-Thr-Gly-Phe-Leu-Thr (DTLET) $(3 \mathrm{nmol})$ increased intake of a $0.15 \%$ saccharin solution by approximately $10 \mathrm{ml}$ over $3 \mathrm{hr}$. Water was available simultaneously, but intake was minimal. The selective kappa agonist U-50,488H did not increase intake of the saccharin solution. Naloxone (30 and $100 \mu \mathrm{g}$, ICV) caused a $44 \%$ reduction in saccharin solution intake in the first hour; two- and three-hour cumulative intakes were not different from control. DAGO and DTLET were also tested when rats were given a weaker saccharin solution $(0.006 \%)$ along with water. Both agonists caused small increases in saccharin and water intake, but the increases above baseline were much smaller than those observed with the more palatable $0.15 \%$ saccharin solution. These results are consistent with reports by others which suggest that endogenous opioids influence taste preferences or palatability. Further, they indicate a role for central mu and delta opioid receptors in the mediation of this influence.
\end{abstract}

Opioids Saccharin intake Naloxone Reward Palatability Taste preference Drinking

IT has been hypothesized that endogenous opioid systems play a role in the mediation of the palatability or reward value of food [see $(10,39)]$. This suggestion is based in part on studies which found that opioid antagonists cause a reduction in the intake of sweet-tasting liquids, such as sucrose, glucose and saccharin solutions $(8,14,24,28,31,33)$, and in the intake of salt solutions $(9,11)$ and ethanol $(40)$. This effect is evident even when typical postingestional sequelae of ingestion are prevented via gastric fistulas (sham-drinking) $(27,41)$. According to the above mentioned hypothesis, intake is reduced because opioid blockade renders the solutions less palatable or rewarding. Consistent with this hypothesis, opioid-receptor-deficient mice display a reduced preference for saccharin solutions (47).

Several studies suggest that the effect of opioid antagonists on the intake of palatable liquids is not due simply to a reduction in water intake or to a general suppression of ingestive behavior. When water and saccharin solutions are available simultaneously, naloxone causes a selective reduction in saccharin intake $(8,28$, 42). Levine et al. (30) found that naloxone was more effective in reducing the intakes of saccharin, sucrose, saline and $\mathrm{HCl}$ solutions than in reducing intakes of water or quinine solution. Lynch (31) and Lynch and Libby (33) reported that the intakes of certain concentrations of saccharin solutions are more affected by naloxone than others. A selectivity in the effects of opioid antagonists is also indicated in the human studies of Fantino et al. (17), who found that naltrexone decreased the pleasantness ratings of glucose solutions and food-related odors but not salt solutions or nonfoodrelated odors.

If opioid blockade causes a decreased preference for otherwise highly palatable solutions, one might predict that an opioid agonist would have the reverse effect, i.e., cause an increased preference. Calcagnetti and Reid (5) and Bertino et al. (2) found this to be true for morphine, which increased preference ratios for saccharin and saline solutions in rats on a water-deprivation schedule. Morphine also stimulated the intake of certain saccharin solutions in nondeprived rats $(5,33)$. A low dose of the selective kappa agonist $\mathrm{U}-50,488 \mathrm{H}$ was found to facilitate the acquisition of a preference for a $20 \%$ sucrose solution (32). Thus, opioid agonists and antagonists appear to exert opposite influences on taste preferences.

The suggestion of opioid involvement in the taste, palatability or rewarding aspects of foods or fluids presupposes that opioid systems are activated in response to palatable tastes. The results of several studies suggest that this may occur. Dum et al. (16) found that consumption of a highly palatable food (chocolate milk or candy) caused a decrease in ${ }^{3} \mathrm{H}$-etorphine binding and in $\beta$ endorphin content in the rat hypothalamus. These changes were attributed to an increased release of $\beta$-endorphin. However, it is 
not clear whether the changes were due to the palatability of the food or simply to the act of ingestion, since the control groups were given water or standard lab chow and consumed nothing. Bergmann et al. (1) found that chronic exposure to a glucosesaccharin solution decreased morphine-induced analgesia. They suggest that opiate tolerance develops as a result of sweet taste-induced release of endogenous opioids. This effect may not be specifically related to the ingestion of sweet tastes, however, as Holder (23) has reported that the analgesic effect of morphine was also reduced by the ingestion of a quinine or a sodium chloride solution. In 10-day-old rat pups, Blass et al. (4) have shown that oral infusion of sucrose causes a naltrexone-reversible increase in paw-lift latencies in the hot-plate analgesia test and a naltrexonereversible decrease in distress vocalizations in isolated pups. Thus, although these studies do not directly establish a role for endogenous opioids in the mediation of palatability, they do indicate that certain tastes can activate endogenous opioid systems.

Morphine, the primary agonist used in the behavioral studies discussed above, is somewhat selective for mu opioid receptors. However, much evidence suggests a role for central mu, kappa and delta receptors in the control of food intake $(10,19,21,29)$. Therefore, in the experiments reported here, we have used selective agonists of these three receptor types. Saccharin and water intake were measured after intracerebroventricular injections of opioid agonists or naloxone. These drugs were tested in nondeprived rats, such that the taste of the solutions presumably provides the primary incentive to drink. The use of nondeprived animals also eliminates the potentially confounding variable of deprivation-induced changes in opioid levels or receptor binding $(3,35,36,38)$. These studies, then, will determine whether the effects of selective agonists delivered directly into the brain are similar to those observed after systemic administration of morphine.

\section{METHOD}

\section{Animals and Surgery}

Male Sprague-Dawley rats weighing 243-308 $\mathrm{g}$ at the time of surgery were used in all experiments. For the DAGO and DTLET experiments described below, rats (total $n=19$ ) were obtained from Charles River Laboratories, Inc. (Wilmington, MA). In the remaining experiments, rats (total $n=20$ ) were obtained from Harlan Sprague Dawley, Inc. (Indianapolis, IN). They were individually housed in stainless steel cages, and food and water were available ad lib except as described below. Lights were on for 12 hours daily, and all experiments began in the first half of the light period. A 20 -gauge cannula was implanted into the right lateral ventricle of each rat with techniques similar to those previously reported (20). Under Nembutal anesthesia (40 mg/kg), the cannula was placed $1.0 \mathrm{~mm}$ posterior and $1.5 \mathrm{~mm}$ lateral to bregma and $3.5-4.5 \mathrm{~mm}$ below the surface of the skull. The incisor bar was set at $3.3 \mathrm{~mm}$ below the interaural line. The cannula was affixed to two screws in the skull with dental cement, and the wound was closed with a wound clip. Cannula placement was verified behaviorally by the observation of a drinking response to an ICV injection of angiotensin II (AII, $250 \mathrm{ng}$ ). AII was injected at the completion of drug testing, and only those rats which drank $5 \mathrm{ml}$ or more in the 30 minutes following injection were included in data analyses.

\section{Saccharin Training Sessions}

At least two days after surgery, rats were deprived of water overnight. The next day, they were moved to novel individual test cages with no food or water. One hour after being placed in these cages, a $25-\mathrm{ml}$ graduated buret fitted with a stainless steel sipper tube was attached to the front of each cage. For approximately one-half of the rats, the buret contained a $0.15 \%$ sodium saccharin solution $(\mathrm{w} / \mathrm{v})$; the remaining rats received a $0.006 \%$ saccharin solution. They were allowed two hours of access to these liquids, after which they were returned to their home cages. This procedure was repeated daily for nine additional days, except that on all subsequent days, two burets were attached to each cage: one contained tap water and the other contained the saccharin solution. Each rat was given the same saccharin concentration throughout the entire experiment. Positions of the water and saccharin burets were reversed daily to prevent the formation of position preferences. To prevent rats from simply drinking indiscriminately from the first buret placed on the cage, a "forced sampling" technique was used $(5,42)$. First, one buret was placed on the cage. After the rat had taken a few licks at the spout, this buret was removed and the other buret was put in place. After a few licks at the second solution, the buret was removed, after which both burets were replaced simultaneously. This procedure was not used if a rat did not immediately begin to drink.

Water was returned to the home cages after the first training session, and was available throughout the remainder of the experiment with the exception of the first hour in the test cages. The purpose of the deprivation prior to the first session was to force the rats to sample the novel saccharin solutions. Food was available in the home cages but not the test cages.

\section{Test Procedures}

After nine nondeprived training days, saccharin intake was measured in response to $\mathrm{ICV}$ injections of $\left[\mathrm{D}-\mathrm{Ala}^{2}, \mathrm{MePhe}^{4}\right.$, Gly-ol ${ }^{5}$ ]enkephalin (DAGO), a selective agonist at mu opioid receptors $(12,22)$. On the first test day, rats in both saccharin concentration groups $(0.15$ or $0.006 \%)$ were given ICV injections of 0,1 or $3 \mathrm{nmol}$ of DAGO in a $5 \mu \mathrm{l}$ volume. These doses were chosen because they are in or below the range of doses which stimulate food intake [ $(20,21)$ and unpublished observations]. DAGO was dissolved in saline, which also served as the placebo injection. Injections were made with a 24-gauge injector which extended $1.0 \mathrm{~mm}$ beyond the tip of the guide cannula. These injectors were connected to $10-\mu$ l glass syringes with polyethylene tubing. Injections were given at the time the rats were transferred to the test cages, and burets (one containing water, one saccharin) were placed on the cages 1 hour later. Thus, the first opportunity to ingest saccharin was one hour after DAGO injection. This delay was imposed because in previous studies we have found that DAGO in this dose range produces a cataleptic state which dissipates within an hour. On test days, rats were given 3 hours access to saccharin (and water), after which they were returned to their home cages. Saccharin and water intakes were measured every hour, and burets were refilled as needed. The test procedure was repeated two additional times, and every rat was tested with saline and with both doses of DAGO. Test days were two days apart, and a normal 2-hour training session was given on the intervening days (no injections). Injection orders for testing the three doses were counterbalanced, and every dose was tested in at least two rats on each test day.

Mean intakes and the variances of intake were markedly greater in rats with access to the $0.15 \%$ saccharin compared to those receiving $0.006 \%$ saccharin. Therefore, analyses were performed separately for each concentration. Initially, cumulative intake data for the group receiving $0.006 \%$ saccharin were analyzed with a three-factor analysis of variance (ANOVA): dose (3 levels) $\times$ fluid (water vs. saccharin) $\times$ time ( 3 levels). When rats had access to the $0.15 \%$ concentration, however, water intake was negligible 
$(<0.1 \mathrm{ml})$ and was not analyzed. A 2-factor ANOVA (dose $x$ time) was therefore used to analyze saccharin intake. Because time was found to be a significant main effect in all initial analyses, separate analyses were performed at each time point. Dunnett's test (one-tailed) was then used at each measurement to compare saccharin and water intake in each DAGO condition to the control (saline) condition.

After the final DAGO trial, the rats were given five consecutive training days as described above. They were then used to test the effects of Tyr-D-Thr-Gly-Phe-Leu-Thr (DTLET), a selective agonist of delta opioid receptors $(18,48)$. They were tested in three trials in a manner identical to that described above for DAGO, with one exception. On test days, burets were placed on the test cages 30 minutes after injection, as opposed to 1 hour postinjection for DAGO. This shorter interval was used because the behavioral depression observed after DTLET injections is less pronounced and shorter in duration than that observed after equimolar doses of DAGO.

A second group of animals were cannulated and trained to drink saccharin in a manner similar to that described above. In this group of rats, however, all rats received $0.15 \%$ saccharin; $0.006 \%$ saccharin was not used. On the first test day (after 11 training days), these rats were divided into two groups. One group was tested with $U-50,488 \mathrm{H}$, a selective agonist at kappa opioid receptors (46). The doses used were 0,30 and $100 \mathrm{nmol}$. The remaining rats were tested with the opioid antagonist naloxone hydrochloride $(0,30$ and $100 \mu \mathrm{g} ; 0,83$ and $275 \mathrm{nmol})$. Naloxone and $\mathrm{U}-50,488 \mathrm{H}$ were dissolved in distilled water, which also served as the placebo injection. Injections were given 45 minutes after placement into the test cages, and burets were placed on the cages 15 minutes after injection. Cannula patencies were confirmed prior to the beginning of saccharin training sessions.

DAGO, DTLET and naloxone hydrochloride were purchased from Sigma Chemical Co. (St. Louis, MO). U-50,488H was purchased from the Upjohn Co. (Kalamazoo, MI).

\section{RESULTS}

In nondeprived rats trained to drink either $0.15 \%$ saccharin or water, DAGO ( $3 \mathrm{nmol})$ caused a large increase in cumulative saccharin intake measured at 1,2 and 3 hours (Fig. 1). Intake after injection of the low dose $(1 \mathrm{nmol})$ was increased, but failed to achieve statistical significance. In this nondeprived state, the mean intake of water in all three drug treatment conditions was negligible (less than $0.1 \mathrm{ml}$ ) and therefore was not analyzed.

Intakes were much lower in rats receiving the $0.006 \%$ saccharin solution (Fig. 2). Data from one animal were discarded because its abnormally high intake after the high dose suggested that it had been water deprived overnight, perhaps due to an obstructed drinking tube in the home cage. In saline-treated animals, total intake (water $+0.006 \%$ saccharin) was less than $1.0 \mathrm{ml}$. Nevertheless, there were small but significant increases in intake after injections of DAGO. In a two-factor ANOVA (dose $\times$ fluid), there was a significant effect of dose at 1,2 and 3 hours, $F(2,12)=11.0,20.13$ and 23.21 , all $p$ 's $<0.005$; the fluid effect (water vs. saccharin) and the dose $\times$ fluid interaction were not significant. Dunnett's tests indicated that the $3 \mathrm{nmol}$ dose significantly increased cumulative water intake at 1,2 and 3 hours and increased saccharin intake at 2 and 3 hours.

DTLET had an effect similar to that of DAGO (Fig. 3). The 3 nmol dose significantly increased cumulative 1-, 2- and 3-hr intake of $0.15 \%$ saccharin, whereas water intake remained below $1.0 \mathrm{ml}$. The $1 \mathrm{nmol}$ dose also elevated intake, but the increase was not statistically reliable. The effect of DTLET on $0.006 \%$ saccharin intake also resembles that of DAGO. Total intake was below 1.0

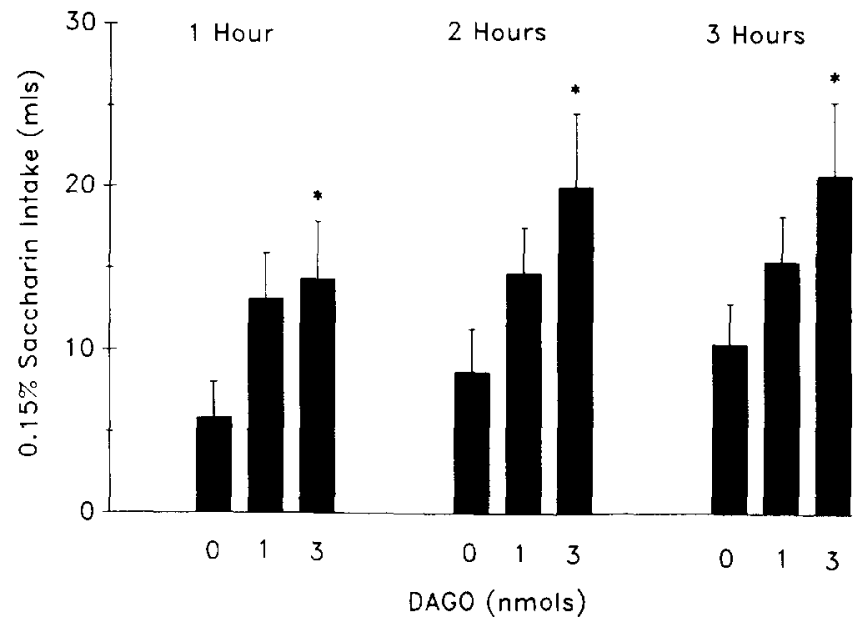

FIG. 1. Cumulative intake of a $0.15 \%$ saccharin solution following ICV injections of the mu agonist DAGO (mean+S.E.M.). All rats $(n=10)$ were tested in the nondeprived condition, and each rat was tested with all doses. Water was available during testing, but mean intake was always less than $0.1 \mathrm{ml}$ and is not shown. Asterisks indicate significant increases above the corresponding $0 \mathrm{nmol}(\mathrm{NaCl})$ condition $(p<0.05$, one-tailed Dunnett's test)

$\mathrm{ml}$ in the control condition, and the maximum total intake was only $3.5 \mathrm{ml}$ ( $3 \mathrm{nmol}$ condition). An ANOVA of dose $\times$ fluid indicated a significant main effect of dose at 1,2 and 3 hours, $\mathrm{F}(2,14)=8.81,11.81$ and 11.6 , all $p$ 's $<0.01$, and a significant main effect of fluid at 1,2 and 3 hours, $F(1,7)=8.17,9.12$, and 8.39 , all $p$ 's $<0.025$. The interaction was not significant at any time point. Dunnett's tests indicated that at each hour, the $1 \mathrm{nmol}$ dose of DTLET stimulated water and saccharin intake and that the $3 \mathrm{nmol}$ dose stimulated only saccharin intake (Fig. 2).

Unexpectedly, U-50,488H did not stimulate saccharin intake. There was a tendency, in fact, for intake to be reduced (Fig. 4). Naloxone caused a short-lived reduction in saccharin intake (Fig. 5). Both doses decreased 1-hour intake by $44 \%$, but 2- and 3-hour cumulative intakes were not different from baseline. Mean water intake was not more than $0.2 \mathrm{ml}$ in any condition. No behavioral depression was apparent following naloxone or $\mathrm{U}-50,488 \mathrm{H}$ administration.

\section{DISCUSSION}

Several experiments were performed to determine whether central injections of selective opioid agonists and naloxone would affect the amount of saccharin solution consumed by nondeprived rats. As discussed in the Introduction, systemically administered naloxone and morphine cause decreases and increases, respectively, in saccharin intake or preference $(5,8,31,33,42)$. We found that in nondeprived rats drinking a highly palatable saccharin solution, the selective mu receptor agonist DAGO and the selective delta receptor agonist DTLET produced considerable increases (greater than $10 \mathrm{ml}$ ) in intake. These increases were selective for saccharin, as water intake was minimal. On the other hand, the administration of the selective kappa agonist $U-50,488 \mathrm{H}$ resulted in a slight decrease in saccharin intake. As predicted, naloxone caused a short-lived decrease in intake. These studies, then, are in general agreement with reports by others and suggest that opioids exert an influence on the palatability and/or reward value of sweet taste [see $(10,39)$ ].

The failure of $\mathrm{U}-50,488 \mathrm{H}$ to increase saccharin intake was 


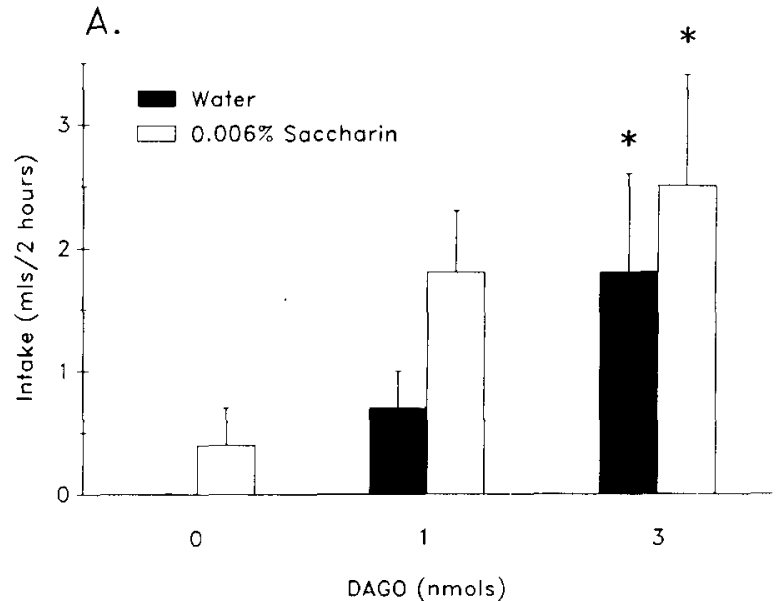

B.

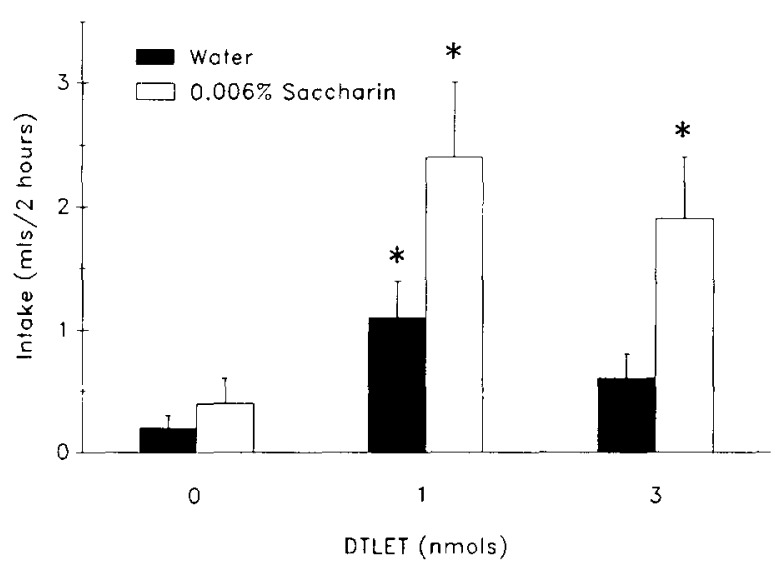

FIG. 2. Cumulative two-hour intake of water and a $0.006 \%$ saccharin solution (mean +S.E.M.) following ICV injections of the mu agonist DAGO (A) or the delta agonist DTLET (B). All rats $(n=7$ for DAGO, $\mathrm{n}=8$ for DTLET) were tested in the nondeprived condition, and each rat was tested with all doses. Similar patterns were observed at 1 and 3 hours. Asterisks indicate significant increases above the corresponding $0 \mathrm{nmol}$ $(\mathrm{NaCl})$ condition $(p<0.05$, one-tailed Dunnett's test).

unexpected in view of the findings that it stimulates food intake in nondeprived rats $[(26,37)$ and unpublished observations]. Lynch and Burns (32) have reported that a small dose of U-50,488H $(0.1 \mathrm{mg} / \mathrm{kg}$, administered subcutaneously) facilitated the intake of a $20 \%$ sucrose solution in nondeprived rats; a higher dose $(1.0 \mathrm{mg} / \mathrm{kg})$ inhibited sucrose intake. If the rats they used weighed less than $500 \mathrm{~g}$, the total amount of agonist injected at their low dose is equal to or less than the high dose we injected directly into the brain $(100 \mathrm{nmol}=46.5 \mu \mathrm{g})$. It is possible, then, that our failure to detect increases in intake is a result of excessive doses of the drug.

It has been reported that opioids stimulate water intake under some conditions $(6,7,34)$. The possibility exists, therefore, that the increased saccharin intake reported here represents a nonspecific hyperdipsia rather than an enhancement of the palatability or reward value of the solutions. If this were the case, however, one would expect similar increases in intake in rats receiving the $0.006 \%$ solution and in rats receiving the $0.15 \%$ solution. With the $0.006 \%$ solution, however, intake was only slightly increased. Because rats were apparently indifferent to saccharin at this concentration, these small increases in intake may be attributable

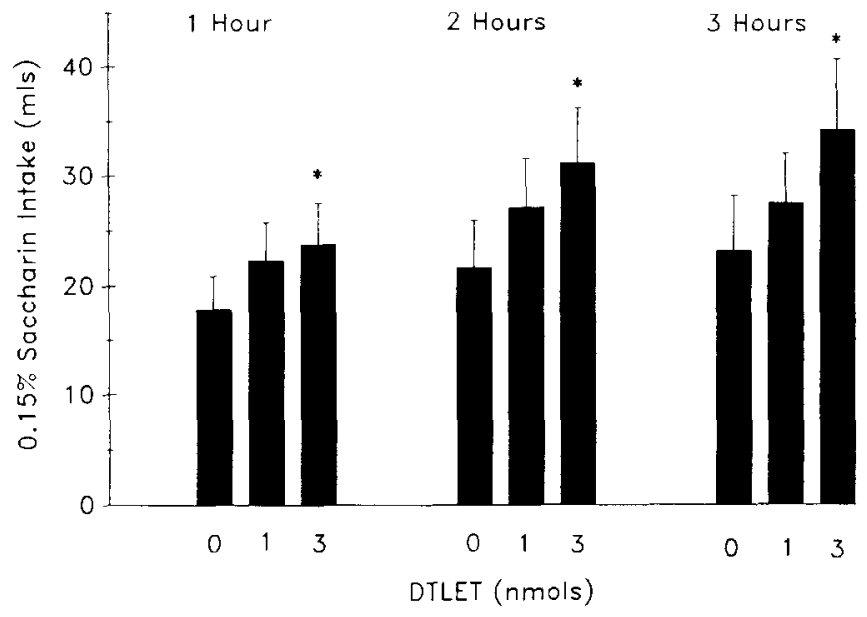

FIG. 3. Cumulative intake of a $0.15 \%$ saccharin solution following ICV injections of the delta agonist DTLET (mean+S.E.M.). All rats $(n=10)$ were tested in the nondeprived condition, and each rat was tested with all doses. Water was available during testing, but mean intake was always less than $1.0 \mathrm{ml}$ and is not shown. Asterisks indicate significant increases above the corresponding $0 \mathrm{nmol}(\mathrm{NaCl})$ condition $(p<0.05$, one-tailed Dunnett's test).

to the general dipsogenic effect of the agonists. As shown in Figs. $1-3$, the increases in intake were much greater in rats receiving $0.15 \%$ saccharin than in those receiving $0.006 \%$ saccharin. Thus, the effects of DAGO and DTLET on the intake of the more palatable $0.15 \%$ solution cannot be attributed to nonspecific increases in fluid intake. These results are similar to those of Calcagnetti and Reid (5), who found that morphine (SC) increased the intake of $0.05,0.15$ and $1.0 \%$ saccharin but not of 0.006 or $0.5 \%$ saccharin.

The present results can also be viewed as being consistent with the suggestion that opioid agonists and antagonists exert influences on the maintenance of ingestion rather than on its initiation [see (10)]. Under baseline conditions (no injection or a placebo injection), nondeprived rats readily drank a $0.15 \%$ saccharin

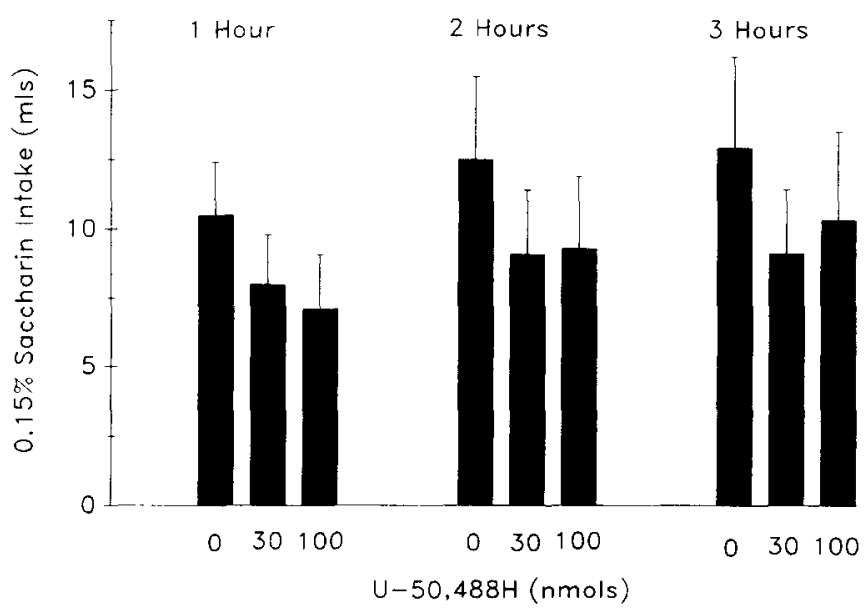

FIG. 4. Cumulative intake of a $0.15 \%$ saccharin solution following ICV injections of the kappa agonist U-50,488H (mean+S.E.M.). All rats $(\mathrm{n}=9)$ were tested in the nondeprived condition, and each rat was tested with all doses. Water was available during testing, but mean intake was always less than $0.2 \mathrm{ml}$ and is not shown. 


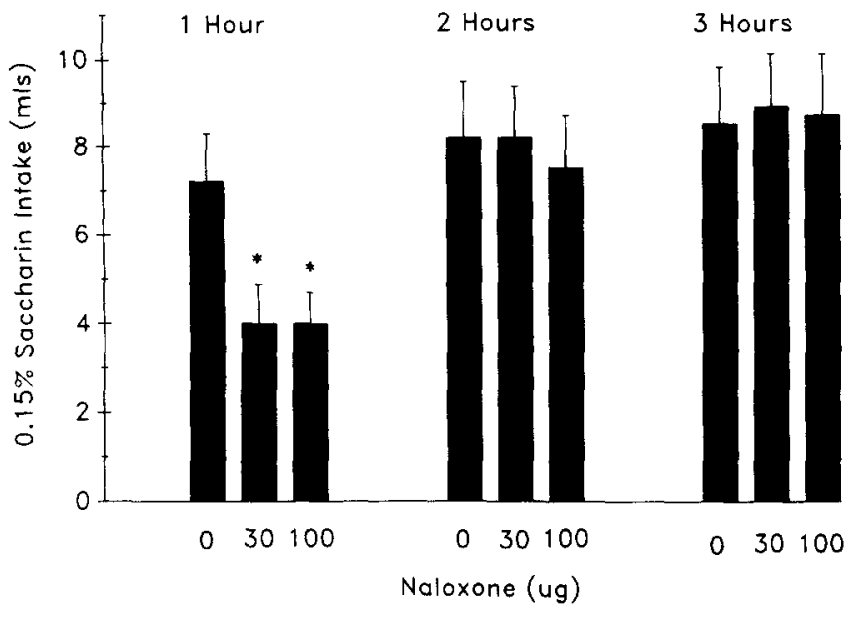

FIG. 5. Cumulative intake of a $0.15 \%$ saccharin solution following ICV injections of the opioid antagonist naloxone (mean+S.E.M.). All rats $(n=10)$ were tested in the nondeprived condition, and each rat was tested with all doses. Water was available during testing, but mean intake was less than $0.1 \mathrm{ml}$ and is not shown. Asterisks indicate significant decreases below the corresponding $0 \mathrm{nmol}$ (water) condition $(p<0.05$, one-tailed Dunnett's test).

solution; this consumption was augmented after DAGO and DTLET injections and decreased after naloxone injections. On the other hand, baseline intake of $0.006 \%$ saccharin was below $0.5 \mathrm{ml}$ over the course of three hours. The smaller effects of DAGO and DTLET with this concentration, then, may be due to the fact that there was little ingestion to maintain. That opioids might affect the maintenance rather than the initiation of intake is compatible with the hypothesis that opioids affect the palatability or reward value of food or fluids, since some consumption would be necessary in order to detect a change in palatability.

In contrast to the above-noted studies in which opioid agonists stimulated water intake, decreases in water intake have been reported after central administration of a number of opioid peptides and after systemic administration of several nonpeptide agonists $(13,15,25,34,43)$. Whether intake is increased or decreased may depend on the dose of the particular agonist being studied, the hydrational state of the animal, and the duration of the test period $(6,14,34,44)$. As an example of the importance of the latter factor, Czirr and Reid (14) found that in deprived rats, morphine reduced the intake of a $5.0 \%$ sucrose solution in short tests (10 or 18 minutes), but increased intake when tests lasted 58 or 100 minutes. Similarly, in studies of water intake, Cantalamessa et al. (6) reported that the opioid agonist [D-Ala ${ }^{2}, \mathrm{D}$ Leu ${ }^{5}$ ]enkephalin reduced 30-minute intake, but increased 90 - and 120-minute intake. A factor intimately related to test duration is the interval between drug injection and the beginning of the drinking tests. In the present experiments, there was a one-hour delay between DAGO injections and the beginning of the intake trials. There was a 30-minute interval for DTLET tests, and a 15 -minute interval for $\mathrm{U}-50,488 \mathrm{H}$ and naloxone. These longer intervals for DAGO and DTLET were used to allow any nonspecific behavioral suppression to subside before introducing water and saccharin solution. Had the intake trials started immediately after injection, it is possible that DAGO would have caused a decrease in saccharin intake, as the $3 \mathrm{nmol}$ dose initially caused catalepsy. Thus, a careful consideration of the details of methodology might reconcile some of the apparent inconsistencies in the literature.

In summary, the intake of palatable saccharin solution was increased by central injections of selective agonists of mu and delta opioid receptors. These increases were observed in rats which were not food or water deprived, such that the taste of the solution presumably provided the primary incentive to drink Under similar conditions, central injections of naloxone caused a decrease in saccharin intake. The kappa agonist U-50,488H caused a slight decrease in intake, but this effect may be the result of excessive doses. These results are in general agreement with the hypothesis that opioids play a role in the mediation of palatability or the rewarding aspects of food.

\section{ACKNOWLEDGEMENT}

This research was supported by NIDA grant DA05471.

\section{REFERENCES}

1. Bergmann, F.; Lieblich, I.; Cohen, E.; Ganchrow, J, R. Influence of intake of sweet solutions on the analgesic effect of a low dose of morphine in randomly bred rats. Behav. Neural Biol. 44:347-353; 1985.

2. Bertino, M.; Abelson, M. L.; Marglin, S. H.; Neuman, R.; Burkhardt, C. A.; Reid, L. D. A small dose of morphine increases intake of and preference for isotonic saline among rats. Pharmacol. Biochem. Behav. 29:617-623; 1988.

3. Blake, M. J.; Stein, E. A.; Czech, D. A. Drinking-induced alterations in reward pathways: an in vivo autoradiographic analysis. Brain Res. 413:111-119; 1987

4. Blass, E.; Fitzgerald, E.; Kehoe, P. Interactions between sucrose, pain and isolation distress. Pharmacol. Biochem. Behav. 26:483-489; 1987.

5. Calcagnetti, D. J.; Reid, L. D. Morphine and acceptability of putative reinforcers. Pharmacol. Biochem. Behav. 18:567-569; 1983.

6. Cantalamessa, F.; de Caro, G.; Massi, M.; Micossi, L. G. Stimulation of drinking behavior and of renin release induced by intracerebroventricular injections of D-Ala ${ }^{2}, \mathrm{D}-\mathrm{Leu}^{5}$-enkephalin to rats. Pharmacol. Res. Commun. 14:141-152; 1982.

7. Cooper, S. J. Behaviorally-specific hyperdipsia in the non-deprived rat following acute morphine treatment. Neuropharmacology 20: 469-472; 1981 .

8. Cooper, S. J. Effects of opiate agonists and antagonists on fluid intake and saccharin choice in the rat. Neuropharmacology 22:323-328;
1983.

9. Cooper, S. J.; Gilbert, D. B. Naloxone suppresses fluid consumption in tests of choice between sodium chloride solutions and water in male and female water-deprived rats. Psychopharmacology (Berlin) 84: 362-367; 1984

10. Cooper, S. J.; Jackson, A.; Kirkham, T. C.; Turkish, S. Endorphins, opiates and food intake. In: Rodgers, R. J.; Cooper, S. J., eds. Endorphins, opiates and behavioral processes. New York: John Wiley and Sons; 1988:143-186.

11. Cooper, S. J.; Turkish, S. Effects of naloxone and its quaternary analogue on fluid consumption in water-deprived rats. Neuropharmacology 22:797-800; 1983 .

12. Corbett, A. D.; Gillan, M. G. C.; Kosterlitz, H. W.; McKnight, A. T.; Paterson, S. J.; Robson, L. E. Selectivities of opioid peptide analogues as agonists and antagonists at the $\delta$-receptor. $\mathrm{Br}$. J. Pharmacol. 83:271-279; 1984

13. Czech, D. A.; Blake, M. J.; Stein, E. A. Drinking behavior is modulated by CNS administration of opioids in the rat. Appetite 5:15-24; 1984

14. Czirr, S. A.; Reid, L. D. Demonstrating morphine's potentiating effects on sucrose-intake. Brain Res. Bull. 17:639-642; 1986.

15. de Caro, G.; Massi, M.; Micossi, L. G.; Perfumi, M. Effect of dermorphin and related peptides on drinking behavior of the rat. In: Muller, E. E.; Genazzani, A. R., eds. Central and peripheral endorphins: Basic and clinical aspects. New York: Raven Press; 
1984:145-149.

16. Dum, J.; Gramsch, C.; Herz, A. Activation of hypothalamic $\beta$ endorphin pools by reward induced by highly palatable food. Pharmacol. Biochem. Behav. 18:443-447; 1983.

17. Fantino, M.; Hosotte, J.; Apfelbaum, M. An opioid antagonist, naltrexone, reduces preference for sucrose in humans. Am. J. Physiol. 251:R91-R96; 1986

18. Gacel, G.; Zajac, J. M.; Delay-Goyet, P.; Dauge, V.; Roques, B. P. Investigation of the structural parameters involved in the $\mu$ and $\delta$ opioid receptor discrimination of linear enkephalin-related peptides. $\mathbf{J}$. Med. Chem. 31:374-383; 1988.

19. Gosnell, B. A. Central structures involved in opioid-induced feeding. Fed. Proc. 46:163-167; 1987.

20. Gosnell, B. A.; Grace, M.; Levine, A. S. Effects of $\beta$-chlornaltrexamine on food intake, body weight and opioid-induced feeding. Life Sci. 40:1459-1467; 1987.

21. Gosnell, B. A.; Levine, A. S.; Morley, J. E. The stimulation of food intake by selective agonists of mu, kappa and delta opioid receptors. Life Sci. 38:1081-1088; 1986.

22. Handa, B. K.; Lane, A. C.; Lord, J. A. H.; Morgan, B. A.; Rance, M. J.; Smith, C. F. C. Analogues of $\beta-\mathrm{LPH}_{61-64}$ possessing selective agonist activity at $\mu$-opiate receptors. Eur. J. Pharmacol. 70:531-540; 1981.

23. Holder, M. D. Responsivity to pain in rats changed by the ingestion of flavored water. Behav. Neural Biol. 49:45-53; 1988.

24. Holtzman, S. G. Effects of narcotic antagonists on fluid intake in the rat. Life Sci. 16:1465-1470; 1975.

25. Imura, H.; Nakao, K.; Yanaihara, N.; Katsuura, G.; Nakamura, M Potent action of leumorphin on consummatory behaviors in rats: comparison with other opioid peptides. Neuroendocrinology 44 142-148; 1986.

26. Jackson, A.; Cooper, S. J. Effects of kappa opiate agonists on palatable food consumption in non-deprived rats, with and without food preloads. Brain Res. Bull. 15:391-396; 1985.

27. Kirkham, T. C.; Cooper, S. J. Attenuation of sham feeding by naloxone is stereospecific: Evidence for opioid mediation of orosensory reward. Physiol. Behav. 43:845-847; 1988

28. Le Magnen, J.; Marfaing-Jallat, P.; Miceli, D.; Devos, M. Pain modulating and reward systems: A single brain mechanism? Pharmacol. Biochem. Behav. 12:729-733; 1980.

29. Levine, A. S.; Morley, J. E.; Gosnell, B. A.; Billington, C. J.; Bartness, T. J. Opioids and consummatory behavior. Brain Res. Bull. $14: 663-672 ; 1985$

30. Levine, A. S.; Murray, S. S.; Kneip, J.; Grace, M.; Morley, J. E. Flavor enhances the antidipsogenic effect of naloxone. Physiol Behav. 28:23-25; 1982.

31. Lynch, W. C. Opiate blockade inhibits saccharin intake and blocks normal preference acquisition. Pharmacol. Biochem. Behav. 24 $833-836 ; 1986$.

32. Lynch, W. C.; Burns, G. Enhancement of sucrose intake by the kappa opioid agonist U-50,488H persists beyond the period of drug exposure. Soc. Neurosci. Abstr. 13:878; 1987.

33. Lynch, W. C.; Libby, L. Naloxone suppresses intake of highly preferred saccharin solutions in food deprived and sated rats. Life Sci. 33:1909-1914; 1983.

34. Maickel, R. P.; Braude, M. C.: Zabik, J. E. The effects of various narcotic agonists and antagonists on deprivation-induced fluid consumption. Neuropharmacology 16:863-866; 1977.

35. Majeed, N. H.; Lason, W.; Przewlocka, B.; Przewlocki, R. Brain and peripheral opioid peptides after changes in ingestive behavior. Neuroendocrinology 42:267-272; 1986.

36. Mori, M.; Ishihara, H.; Iriuchijima, T. Water deprivation changes naloxone binding in the rat brain. Neuroendocrinology 47:290-293; 1988.

37. Morley, J. E.; Levine, A. S. Involvement of dynorphin and the kappa opioid receptor in feeding. Peptides 4:797-800; 1983.

38. Przewlocki, R.; Lason, W.; Konecka, A. M.; Gramsch, C.; Herz, A.; Reid, L. D. The opioid peptide dynorphin, circadian rhythms, and starvation. Science 219:71-73; 1983 .

39. Reid, L. D. Endogenous opioid peptides and regulation of drinking and feeding. Am. J. Clin. Nutr. 42:1099-1132; 1985.

40. Reid, L. D.; Hunter, G. A. Morphine and naloxone modulate intake of ethanol. Alcohol 1:33-37; 1984.

41. Rockwood, G. A.; Reid, L. D. Naloxone modifies sugar-water intake in rats drinking with open gastric fistulas. Physiol. Behav. 29: $1175-1178 ; 1982$.

42. Siviy, S. M.; Reid, L. D. Endorphinergic modulation of acceptability of putative reinforcers. Appetite 4:249-257; 1983.

43. Spencer, R. L.; Deupree, D.; Hsiao, S.; Mosberg, H. I.; Hruby, V.; Burks, T. F.; Porreca, F. Centrally administered opioid selective agonists inhibit drinking in the rat. Pharmacol. Biochem. Behav. $25: 77-82 ; 1986$.

44. Turkish, S.; Cooper, S. J. Effects of a kappa receptor agonist, ethylketocyclazocine, on water consumption in water-deprived and nondeprived rats in diurnal and nocturnal tests. Pharmacol. Biochem. Behav. 21:47-51; 1984

45. Ukai, M.; Holtzman, S. G. Effects of intrahypothalamic administration of opioid peptides selective for $\mu-, \kappa$ - and $\delta$-receptors on different schedules of water intake in the rat. Brain Res. 459:275-281; 1988.

46. VonVoigtlander, P. F.; Lahti, R. A.; Ludens, J. H. U50,488: A selective and structurally novel non-mu (kappa) opioid agonist. J. Pharmacol. Exp. Ther. 224:7-12; 1983.

47. Yirmaya, R.; Lieblich, I.; Liebeskind, J. C. Reduced saccharin preference in CXBK (opioid receptor-deficient) mice. Brain Res. 438:339-342; 1988

48. Zajac, J. M.; Gacel, G.; Petit, F.; Dodey, P.; Rossignol, P.; Roques, B. P. Deltakephalin, Tyr-D-Thr-Gly-Phe-Leu-Thr: A new highly potent and fully specific agonist for opiate $\delta$-receptors. Biochem. Biophys. Res. Commun. 111:390-397; 1983. 